\title{
Original Article \\ Human Resource for Climate Change Response Policy Implementation in Ho Chi Minh City: Situation and Solutions
}

\author{
Ngo Hoai Son ${ }^{1}$, Nguyen Van $\mathrm{Hoa}^{2, *}$ \\ ${ }^{1}$ International University, Vietnam National University, HCMC, Quarter 6, Linh Trung, \\ Thu Duc, Ho Chi Minh City, Vietnam \\ ${ }^{2}$ Vietnam Institute of Science Technology and Innovation, Ministry of Science and Technology, \\ 38 Ngo Quyen, Hoan Kiem, Hanoi, Vietnam
}

Received 15 July 2019

Revised 03 December 2019; Accepted 20 December 2019

\begin{abstract}
Being severely affected by climate change, Ho Chi Minh City needs to focus on developing human resource for its climate change response policy. This is because human resource is a key factor for a successful response. This paper uses secondary data from the Department of Natural Resources and Environment of Ho Chi Minh City to analyze the current situation of the city's two main groups of human resources for climate change: a core group and a complementary group. The data show that, although the core group is highly qualified, it lacks staff with deep expertise in policy and climate change. As for the complementary group, the city has not focused on training it in both short and long terms. In order to improve the effectiveness of climate change response in the coming years, Ho Chi Minh City needs to implement at least three solutions: (01) recruiting additional staff with expertise in policies and climate change; (02) promoting training for the core personnel; and (03) building and implementing both short and long-term training plans for complementary staff.
\end{abstract}

Keywords: Human resource, climate change response, policy implementation, Ho Chi Minh City.

\footnotetext{
${ }^{*}$ Corresponding author.

E-mail address: htvm2019@gmail.com
}

https://doi.org/10.25073/2588-1116/vnupam.4190 


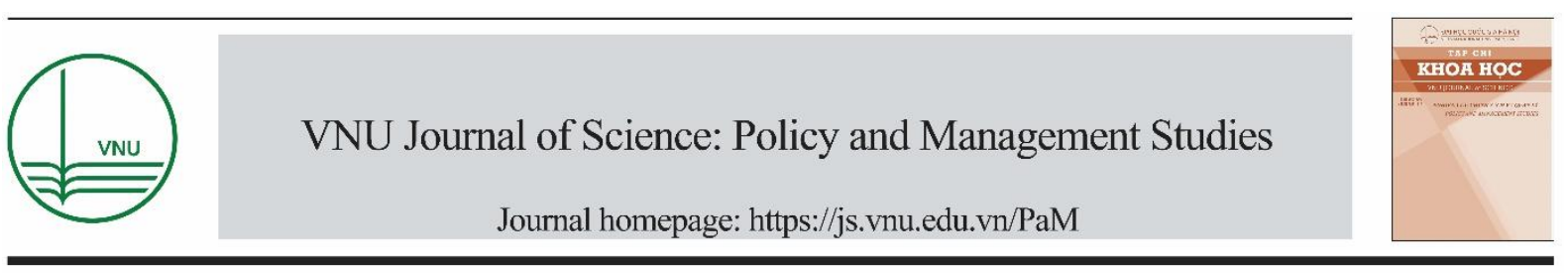

\title{
Nhân lực thực hiện chính sách ứng phó biến đổi khí hậu tại thành phố Hồ Chí Minh: Thực trạng và giải pháp
}

\author{
Ngô Hoài Sơn ${ }^{1}$, Nguyễn Văn Hoà2,* \\ ${ }^{1}$ Truờng Đại học quốc tế, Đại học quốc gia Tp. Hồ Chỉ Minh, Khu phố 6, P. Linh Trung, \\ Q. Thủ Đức, Tp. HCM, Việt Nam \\ ${ }^{2}$ Học viện Khoa học Công nghệ và Đổi mói sáng tạo, Bộ Khoa học và Công nghệ, \\ 38 Ngô Quyền, Hoàn Kiếm, Hà Nội, Việt Nam \\ Nhận ngày 15 tháng 7 năm 2019 \\ Chỉnh sửa ngày 03 tháng 12 năm 2019; Chấp nhận đăng ngày 20 tháng 12 năm 2019
}

\begin{abstract}
Tóm tắt: Là một địa phương bị ảnh hưởng nghiêm trọng bởi biến đổi khí hậu, Thành phố Hồ Chí Minh cần tập trung phát triển nhân lực cho công cuộc ứng phó biến đổi khí hậu của Thành phố. Bởi đây là yếu tố giữ vai trò then chốt trong ứng phó biến đồi khí hậu thành công. Bài viết sử dụng phương pháp phân tích số liệu thứ cấp từ Sở Tài nguyên và Môi trường Thành phố Hồ Chí Minh để phân tích thực trạng nhân lực về biến đổi khí hậu của Thành phố theo 02 nhóm chính là nhóm cốt lõi và nhóm bổ trợ. Các số liệu cho thấy, tuy nhóm nhân lực cốt lõi có trình độ cao nhưng lại thiếu nhân lực có chuyên môn sâu về chính sách và biến đổi khí hậu. Riêng đội ngũ nhân lực bổ trợ, Thành phố chưa chú trọng đến công tác bồi dưỡng cả về ngắn hạn và dài hạn. Để nâng cao hiệu quả ứng phó biến đổi khí hậu trong thời gian tới, Thành phố Hồ Chí Minh cần thực hiện ít nhất 03 giải pháp: (01) bổ sung biên chế có chuyên môn về chính sách và biến đổi khí hậu; (02) đẩy mạnh bồi dưỡng cho nhân lực cốt lõi; và (03) thống kê, xây dựng và thực hiện kế hoạch bồi dưỡng ngắn hạn và dài hạn cho nhân lực bổ trợ.
\end{abstract}

Tư khoá: Nhân lực, thực hiện chính sách, Thành phố Hồ Chí Minh, Ứng phó biến đổi khí hậu.

\section{Mở đầu}

Thành phố Hồ Chí Minh là một trong 10 thành phố trên thế giới bị ảnh hưởng nặng nề nhất bởi biến đổi khí hậu [1, tr.2]; đòi hỏi Thành phố có chính sách và quá trình thực hiện chính sách ứng phó biến đổi khí hậu phù hợp. Giữ vai trò trọng tâm của quá trình thực hiện chính sách là nguồn nhân lực. Xây dựng nguồn nhân lực phù hợp cho ứng phó biến đổi khí hậu là vấn đề bền vững và cấp thiết hiện nay của Thành phố Hồ Chí Minh. Chính vì vậy mà trong Kế hoạch hành

\footnotetext{
*Tác giả liên hệ.

Địa chi email: htvm2019@gmail.com
}

https://doi.org/10.25073/2588-1116/vnupam.4190 
động ứng phó biến đổi khí hậu đến năm 2025, nâng cao chất lượng nguồn nhân lực là một trong những giải pháp được đặt lên đầu tiên. Để đạt được mục tiêu nghiên cứu trên, bài viết tập trung làm rõ một số vấn đề lý thuyết về thực hiện chính sách ứng phó biến đổi khí hậu; từ đó trình bày khái quát về bộ máy thực hiện chính sách ứng phó biến đổi khí hậu tại Thành phố Hồ Chí Minh; và thực trạng nhân lực thực hiện chính sách ứng phó biến đổi khí hậu tại thành phố Hồ Chí Minh. Bài viết rút ra một số vấn đề đặt ra và giải pháp phát triển nhân lực thực hiện chính sách ứng phó biến đổi khí hậu tại Thành phố Hồ Chí Minh.

\section{Một số vấn đề lý thuyết về thực hiện chính sách ứng phó biến đổi khí hậu ở địa phương}

\subsection{Khái niệm thực hiện chính sách ứng phó biến đổi khi hậu ở địa phương}

Là một bước của quy trình chính sách, thực hiện chính sách được nhiều nhà nghiên cứu quan tâm với nhiều cách hiểu khác. Ferman [2] quan niệm thực hiện chính sách "là những gì xảy ra giữa sự mong đợi của chính sách và kết quả chính sách thu được". Đây là cách hiểu quá chung chung và mơ hồ. "Những gì diễn ra giữa" cách diễn đạt nửa vời, mặc dù nó có thể bao gồm tất cả, nhưng vì quá chung chung nên thực chất khái niệm đó không bao gồm gì cả. Nó không nhấn mạnh đến hành động thực hiện chính sách, mặc dù quá trình thực hiện chính sách cần được hiểu theo nghĩa là các hành động ở mức độ càng chi tiết, cụ thể càng tốt. Để cự thể hoá khái niệm thực hiện chính sách vừa trình bày, Mazmanian và Sabatier $[3$, tr.1] cho rằng "thực hiện chính sách là việc công chức triển khai một quyết định chính sách đã được thông qua để thực hiện quyền lực chính thống".

Trong bối cảnh của Việt Nam, theo quy định của Luật Chính quyền địa phương, chính quyền địa phương bao gồm Hội đồng nhân dân và Uỷ ban nhân dân các cấp. Chính quyền địa phương có chức năng và nhiệm vụ quản lý nhà nước trên phạm vi lãnh thổ mà mình phụ trách.
Theo đó, thực hiện chính sách UPPBĐKH ở địa phương là việc tiến hành các hoạt động, huy động và sử dụng các nguồn lực một cách có kế hoạch để triển khai, đưa vào thực tiễn những chính sách U'PBĐKH do chính quyền trung ương đưa xuống và do chính quyền địa phương ban hành. Từ khái niệm này, có thể rút ra một số vấn đề liên quan đến thực hiện chính sách ƯPBĐKH ở địa phương như sau:

Thú nhất, việc thực hiện chính sách UPBĐKH ở địa phương là những hoạt động mang tính hướng đích có kế hoạch chứ không phải mang tính ngẫu nhiên, cảm hứng.

Thư hai, việc thực hiện chính sách UPBĐKH liên quan đến việc sử dụng hiệu quả các nguồn lực cần thiết có liên quan như nguồn lực con người, tài chính, cộng đồng, thể chế, thông tin và văn hoá địa phương.

Thư $b a$, chính sách được đưa vào thực tế có thể là chính sách được ban hành từ trung ương hoặc/và chính sách do chính địa phương ban hành.

\subsection{Vai trò của nhân lực trong quá trình thực hiện chính sách ứng phó biến đổi khi hậu}

Nguồn nhân lực luôn giữ vai trò trung tâm của quá trình thực hiện chính sách ứng phó biến đổi khí hậu. Tác giả Nguyễn Hữu Hải [4, tr. 139145] đưa ra một số yếu tố ảnh hưởng đến thực hiện chính sách. Trong đó có năng lực thực hiện chính sách của cán bộ, công chức; mức độ tuân thủ các bước trong quy trình tổ chức thực hiện chính sách bên cạnh hàng loạt những yếu tố khác. Tác giả Smith [5] trong quá trình liệt kê một số yếu tố ảnh hường đến quá trình thực hiện chính sách có nhấn mạnh đến nguồn nhân lực thực hiện thông qua việc phân tích khái niệm nhóm tham gia. Tác giả khẳng định cơ quan thực hiện là những chủ thể chính đưa chính sách vào thực tế với những nội hàm quan trọng như cơ cấu tổ chức và nhân sự, sự lãnh đạo trong cơ quan nhà nước.

Tuỳ theo mô hình thực hiện chính sách ứng phó biến đổi khí hậu khác nhau, các yếu tố ảnh hưởng đến thực hiện chính sách ứng phó biến đổi khí hậu ở địa phương cũng khác nhau nhưng đều 
nhấn mạnh đến vai trò không thể thiếu của nguồn nhân lực. Ở Mô hình hơp lý, nguồn nhân lực với sự phân công nhiệm vụ rõ ràng và chi tiết, các tiêu chuẩn phù hợp, và sự giám sát hợp lý là các yếu tố tác động tích cực đến sự thành công của việc thực hiện chính sách [6]. Trong khi đó, $M \hat{o}$ hình quản lý lại nhấn mạnh đến các yếu tố như ngân sách, cấu trúc tổ chức, giao tiếp, sự tham gia của mọi người, thiết bị và công nghệ phù hợp, và địa điểm phù hợp [6]. Mô hình phát triển tổ chức lại nghiêng về các khía cạnh liên quan đến phát triển tổ chức bao gồm sự lãnh đạo hiệu quả, động cơ, sự tham gia của mọi người, xây dựng nhóm, và tính đúng đắn của quyết định [6]. Mô hình thu lại cho rằng những yêu tố ảnh hưởng tới quá trình thực hiện chính sách là sự phân quyền hợp lý cho cấp cơ sở, khả năng, vấn đề kiểm soát hành vi, và sự cam kết của cấp cơ sở. Mô hình chính trị đề cập đến những yếu tố như hạn chế sự phức tạp trong liên đới hành động, khả năng thương lượng cao hơn, hài hòa giữa các nhà chính trị, động cơ chính trị tích cực, và sự tối thiểu hóa áp lực chính trị [6].

Vai trò quan trọng của nguồn nhân lực trong quá trình thực hiện chính sách ứng phó biến đồi khí hậu ở địa phương thể hiện ngay chính từ thực tiễn thực hiện chính sách của một số quốc gia trên thế giới. Có thể lấy thực tế từ Trung Quốc để minh họa. Trong quá trình thực hiện chính sách ứng phó biến đồi khí hậu ở địa phương, Trung Quốc nhận thấy rằng, cán bộ công chức ở địa phương là nhân tố quan trọng nhất quyết định sự thành bại của chính sách này nhưng lại thường không quan tâm đến việc thực hiện chính sách. Điều này làm cho quá trình thực hiện chính sách ứng phó biến đổi khí hậu của Trung Quốc có thể bị gián đoạn, trì trệ và không hiệu quả. Do đó, Trung Quốc tập trung vào nguồn nhân lực là cán bộ, công chức ở địa phương. Chính quyền trung ương bằng quyền lực của mình sử dụng đồng thời "củ cà rốt" (khuyến khích, khen thường) và "cây gậy" (xử phạt) [7]. Chính quyền trung ương Trung Quốc có chế độ khen thưởng cho những cán bộ công chức ở địa phương tích cực và đóng góp nhiều cho việc thực hiện chính sách môi trường như lồng ghép vào hoạt động đánh giá cán bộ, công chức cuối năm, thăng tiến, tăng lương hoặc thưởng, những lợi ích về vật chất khác như (được đi lại miễn phí, miễn phí các dịch vụ giải trí, tham gia bồi dưỡng và du lịch) và những khoản hỗ trợ khác như trợ cấp nhà ở, chăm sóc sức khoẻ và cơ hội được học tập cao hơn. Ngược lại, nếu cán bộ, công chức ở địa phương không thực hiện tốt chính sách biến đổi khí hậu sẽ bi những hình phạt như không được thăng tiến, điều động công tác tới vùng sâu, vùng $\mathrm{xa}$, trong một số ít trường hợp, còn bị sa thải. Những người đứng đầu địa phương (cả của Đảng và chính quyền) phải ký hợp đồng trách nhiệm cá nhân cam kết lồng ghép các yêu cầu về năng lượng và khí phát thải hàng năm tại địa phương của mình [7].

\section{Khái quát về bộ máy thực hiện chính sách ứng phó biến đổi khí hậu tại Thành phố Hồ Chí Minh}

Tại Tp. Hồ Chí Minh, bộ máy thực hiện chính sách ứng phó biến đổi khí gồm các thành phần dưới đây:

Ban chỉ đạo trực thuộc Ủy ban nhân dân Tp. $\mathrm{HCM}$, bao gồm Trưởng Ban là Chủ tịch UBND Tp, 01 Phó ban thường trực là Giám đốc Sở Tài Nguyên \& Môi trường 02 Phó ban là Giám đốc Sở Nông nghiệp \& Phát triển Nông thôn và Giám đốc Sở Kể hoạch-Đầu tư. Ban gồm các thành viên đến từ các Sở, Ban, Ngành; Bộ Chỉ huy Quân sự thành phố; Báo Sài Gòn Giải Phóng.

Ban chỉ đạo thực hiện các nhiệm tham mưu giúp Ủy ban nhân dân thành phố chỉ đạo và tổ chức triển khai thực hiện các nghị quyết, chủ trương, chính sách của Đảng và Nhà nước về các hoạt động liên quan đến biến đổi khí hậu và ứng phó với biến đổi khí hậu trên địa bàn thành phố Hồ Chí Minh. Nghiên cứu và xây dựng Kế hoạch hành động ứng phó với biến đổi khí hậu trình Uỷ ban nhân dân thành phố phê duyệt. Nghiên cứu đề xuất các chính sách khuyến khích phát triển bền vững và giảm nhẹ tác động của biến đổi khí hậu. Ban chỉ đạo được quyền yêu cầu các sở ngành, địa phương, tổ chức, cá nhân cung cấp tài liệu, thông tin và phối hợp triển khai các hoạt động liên quan đến biến đổi khí hậu. Trong 
trường hợp cần giải quyết ứng phó nhanh, ứng phó khẩn cấp liên quan đến biến đổi khí hậu, Ban chỉ đạo có nhiệm vụ phối hợp với các sở ban ngành liên quan, Ủy ban nhân dân quận huyện để tổ chức công tác giảm nhẹ thiệt hại, ứng cứu đối phó khi có tình huống đột xuất xảy ra để hạn chế thiệt hại đến mức thấp nhất; khắc phục hậu quả, sớm phục hồi sản xuất, cơ sở vật chất kỹ thuật và ổn định đời sống nhân dân.

Cơ quan thường trực của Ban chỉ đạo thực hiện Kế hoạch hành động U'PBĐKH là Văn phòng BĐKH. Văn phòng BĐKH gồm có 01 Chánh Văn phòng và 02 Phó Chánh Văn phòng. Văn phòng Biến đổi khí hậu TPHCM được thành lập theo Quyết định số 2816/QĐ-UBND ngày 31/05/2012 của Chủ tịch UBND TP. Văn phòng Biến đổi khí hậu thành phố Hồ Chí Minh (gọi tắt là Văn phòng) trực thuộc Ban chỉ đạo thực hiện kế hoạch hành động ứng phó với biến đổi khí hậu (gọi tắt là Ban chỉ đạo).

Ban chỉ đạo còn có các Tổ chuyên môn được thành lập từ các chuyên viên của các Sở, và Tổ công tác biến đổi khí hậu tại các Sở ngành để phối hợp thực hiện các nhiêm vụ liên quan đến công tác UPBĐKH. Ngoài ra còn thành lập các tổ công tác biến đổi khí hậu tại 24 Quận, huyện của Tp. HCM [8, tr. 27]. Các tổ Biến đổi khí hậu này thuộc Phòng Tài nguyên và môi trường Quận, Huyện.

\section{Thực trạng nhân lực thực hiện chính sách ứng phó biến đổi khí hậu tại thành phố Hồ Chí Minh}

Chủ thể thực hiện chính sách UPBĐKH ở Tp. Hồ Chí Minh bao gồm chủ thể nòng cốt và chủ thể bổ trợ. Chủ thể nòng cốt chịu trách nhiệm chính trong quá trình thực hiện chính sách, chỉ đạo toàn bộ quá trình thực hiện chính sách. Chủ thể bổ trợ là những bên có tham gia triển khai thực hiện với tư cách là thành viên hỗ trợ. Trong quá trình thực hiện chính sách U'PBĐKH tại Tp.Hồ Chí Minh chủ thể thực hiện nòng cốt bao gồm Sở Tài Nguyên Môi trường, Ban UPBĐKH và các tổ chuyên viên giúp việc. Theo đó, nhân lực thực hiện chính sách là cán bộ, công chức làm việc ở các cơ quan này.

Nhân lực thường trực bao gồm công chức làm việc tại Văn phòng biến đổi khí hậu. Hiện tại số lượng biên chế thuộc Văn phòng biến đổi khí hậu là 06 người, với trình độ chuyên môn được thể hiện cụ thể ở Bảng dưới đây.

Bảng 1. Biên chế Văn phòng biến đổi khí hậu

\begin{tabular}{|c|c|c|c|}
\hline $\begin{array}{l}\text { Trình độ chuyên } \\
\text { môn }\end{array}$ & $\begin{array}{l}\text { Số } \\
\text { lượng }\end{array}$ & $\begin{array}{l}\text { Nơi cấp } \\
\text { bằng }\end{array}$ & Tỷ lệ \\
\hline $\begin{array}{l}\text { Tiến sĩ môi } \\
\text { trường }\end{array}$ & 01 & Thái Lan & $33,3 \%$ \\
\hline $\begin{array}{l}\text { Nghiên cứu sinh } \\
\text { về môi trường }\end{array}$ & 01 & Anh & \\
\hline $\begin{array}{l}\text { Thạc sĩ: } \\
\text { 01 Luật môi } \\
\text { trường }\end{array}$ & 03 & $\begin{array}{l}\text { Đại học } \\
\text { RMIT } \\
\text { Việt Nam }\end{array}$ & $50,0 \%$ \\
\hline $\begin{array}{l}02 \text { Môi trường } \\
\text { Cử nhân kế toán }\end{array}$ & 01 & Việt Nam & $17,0 \%$ \\
\hline
\end{tabular}

Bảng số liệu trên cho thấy nhân lực của Văn phòng $\mathrm{BĐKH}$ rất đảm bảo về trình độ bằng cấp và chuyên môn. Văn phòng có tới $83 \%$ từ thạc sĩ trở lên, với $33,3 \%$ là có trình độ tiến sĩ. Điều đáng quan tâm ơn là nhân lực của Văn phòng phần lớn có chuyên môn về môi trường, và tốt nghiệp ở nước ngoài. Có 02 trường hợp thạc sĩ tốt nghiệp ở trong nước nhưng đều là trường nổi tiếng là RMIT của Việt Nam.

Ngoài Văn phòng BĐKH, trong Sở Tài nguyên và Môi trường còn có Phòng Khí tượng thuỷ văn và Biến đổi khí hậu. Phòng có 8 nhân lực và thể hiện ở Bảng dưới đây.

Bảng 2. Nhân lực Phòng khí tượng thủy văn và Biến đổi khí hậu Tp. HCM

\begin{tabular}{lll}
\hline Trình độ & Số lượng & Tỷ lệ $(\%)$ \\
\hline PGS. Tiến sĩ & 01 & 12,5 \\
Tiến sĩ & 01 & 12,5 \\
Thạc sĩ & 06 & 75,0 \\
\hline Tồng & 08 & 100 \\
\hline
\end{tabular}

(Nguồn: Sở Tài nguyên và Môi trường Tp. HCM, 2019 [9]) 
Trong số 8 nhân sự, không có nhân lực nào có trình độ cử nhân, $100 \%$ có trình độ thạc sĩ trở lên. Phòng còn có 01 PGS. TS. chiếm $12,5 \%$, có 01 tiến sĩ chiếm $12,5 \%$, và 06 thạc sĩ chiếm $75 \%$ [8]. Trong số 8 nhân sự này, có tới 04 nhân sự $(50 \%)$ có chuyên môn về Khoa học môi trường và kỹ thuật môi trường, có 01 nhân sự có chuyên môn về đánh giá tác động, kiểm tra và hệ thống quản lý môi trường (nhân sự này đang làm nghiên cứu sinh), 01 nhân sự là Tiến sĩ có chuyên môn về địa lý (khí tượng-khí hậu) tại Liên Xô và 01 nhân sự có chuyên môn Quản trị kinh doanh. Nhân lực của Phòng Khí tượng thuỷ văn và Biến đổi khí hậu có chuyên mình phù hợp và trình độ cao, có thể đáp ứng được chức năng, nhiệm vụ quản lý nhà nước về môi trường trường và UPBĐKH.

Ngoài ra, nhân lực thực hiện U'PBĐKH còn có các Tổ chuyên môn được thành lập từ các chuyên viên của các Sở, và Tổ công tác biến đổi khí hậu tại các Sở ngành để phối hợp thực hiện các nhiêm vụ liên quan đến công tác UPBĐKH. Ngoài ra còn thành lập các tổ công tác biến đổi khí hậu tại 24 Quận, huyện của Tp. HCM [7, tr. 27]. Các tổ Biến đổi khí hậu này thuộc Phòng Tài nguyên và môi trường Quận, Huyện.

\section{Một số vấn đề đặt ra và giải pháp phát triển nhân lực thực hiện chính sách ứng phó biến đổi khí hậu tại Thành phố Hồ Chí Minh}

\subsection{Một số vấn đề đặt ra}

Từ thực tiễn nhân lực thực hiện chính sách ứng phó biến đổi khí hậu ở trên, có thể thấy rằng, mặc dù nhân lực thực hiện chính sách này ở Thành phố về cơ bản là đảm bảo, nhưng vẫn còn một số vấn đề cần tiếp tục hoàn thiện.

Thư nhất, đội ngũ nhân lực cốt lõi hiện tại hoàn toàn đáp ứng về trình độ chuyên môn liên quan đến môi trường và khí tượng, thuỷ văn nói chung. Đây là khía cạnh tính cực. Tuy nhiên chuyên môn về môi trường và khí tượng, thuỷ văn dù có liên quan nhưng vẫn không phải là chuyên môn về ứng phó biến đổi khí hậu. Ứng phó biến đổi khí hậu đòi hỏi có hiểu biết vừa chuyên môn sâu vừa ở khía cạnh chính sách. Đội ngũ cốt lõi hoàn toàn thiếu nhân lực có chuyền môn về chính sách công, về ứng phó biến đổi khí hậu hoặc phát triển bền vững và quản trị dự án về môi trường và biến đổi khí hậu. Sự thiếu hụt này làm cho quá trình tham vấn trong hoạch định và thực hiện chính sách ứng phó biến đổi khí hậu chưa hiệu quả và thiếu bền vững.

Thứ hai, về mặt số lượng, đội ngũ nhân lực cốt lõi có tổng cộng 14 người, trong đó có 01 nhân sự kiêm nhiệm phụ trách toàn bộ các vấn đề về ứng phó biến đồi khí hậu ở Thành phố Hồ Chí Minh thì quá thiếu. Càng thiếu hơn khi 8/14 nhân sự này còn tham gia quản lý nhà nước về môi trường của Thành phố.

Thú $b a$, nguồn nhân lực bổ trợ đang nằm rải rác ở các cơ quan cấp tỉnh và cấp huyện thực hiện nhiệm vụ kiêm nhiệm liên quan đến ứng phó biến đổi khí hậu. Đội ngũ này tuy nhiều nhưng không có chuyên môn. Không những vậy, vấn đề bồi dưỡng về ứng phó biến đổi giành cho đối tượng này vẫn chưa được thực hiện thường xuyên và liên tục. Trên thực tế, chưa có khoá bồi dưỡng theo chức danh nào dành cho vị trí ứng phó biến đổi khí hậu đang được kiêm nhiệm ở các cơ quan. Vấn đề càng đáng quan tâm hơn khi mà Thành phố Hồ Chí Minh chưa có kế hoạch cả trong ngắn và dài hạn về ứng phó biến đổi khí hậu cho đối tượng này.

Thực trạng nhân lực biến đổi khí hậu của Thành phố Hồ Chí Minh cũng là thực trạng chung của cả nước. Theo báo cáo của Bộ TN\&MT, hiện đang có sự mất cân đối và thiếu hụt trong cơ cấu nhân lực của ngành. Trong khi nhân lực quản lý đất đai chiếm $52,2 \%$ thì nhân lực phục vụ trong lĩnh vực khí tượng thủy văn và BĐKH chỉ chiếm $1 \%$. Phó Viện trưởng Viện Khoa học khí tượng thủy văn và môi trường Trần Hồng Thái cho hay, nhu cầu đào tạo nhân lực cho BĐKH đang cực kỳ cấp bách, nhất là ở các địa phương. Trung bình mỗi tỉnh cần ít nhất 10 cán bộ được đào tạo về $\mathrm{BĐKH}$, trong khi hiện hầu hết các địa phương không có cán bộ chuyền môn bởi đây là lĩnh vực quản lý rất mới. Đó là chưa kể khoảng 700 huyện và 9.000 xã trên cả nước đều cần cán bộ có kiến thức về BĐKH [10]. 
Nguyên nhân của những hạn chế vừa trình bày ở trên xuất phát từ nguyên nhân khách quan. Việt Nam chưa có trường đào tạo nguồn nhân lực giành cho UPBĐKH ở trình độ đại học. Trường Đại học Tài nguyên Môi trường được giao nhiệm vụ đào tạo nguồn nhân lực ngành Tài nguyên, môi trường ở bậc đaị học, nhưng cũng mới đang trong giai đoạn chuẩn bị đội ngũ giảng viên cho mở ngành đào tạo nhân lực ứng phó với biến đổi khí hậu với một Bộ môn Biến đồi khí hậu và Phát triển bền vững. Chính vì vậy, khi cần nhân lực, tất cả đều dựa vào đào tạo quốc tế và các chiến dịch truyền thông, nâng cao năng lực mà đối tượng đi học lại được "nhặt" từ các cán bộ chuyên ngành khí tượng thuỷ văn hay một số các chuyên ngành khác có liên quan đi học [11].

\subsection{Một số giải pháp phát triển nhân lực thực hiện chính sách ưng phó biến đổi khi hậu tại Thành phố Hồ Chí Minh}

Để có thể giải quyết vấn đề đặt ra ở trên, trong thời gian tới, Thành phố Hồ Chí Minh cần thực hiện các giải pháp sau:

Trước hết, cần bổ sung nhân lực cốt lõi có chuyên môn về biến đổi khí hậu, phát triển bền vững và chính sách. Thành phố cần xác định lại thực trạng biến đổi khí hậu ở địa phương để từ đó xác định nhu cần nhân sự đang cần. Tuy nhiên, việc tuyển thêm nhân sự có trình độ chuyên môn như vậy đang gặp trở ngại từ kế hoạch tinh giản biên chế của toàn bộ hệ thống nhà nước từ trung ương đến địa phương. Để vượt qua khó khăn nay, có thể chuyển bớt một nhân sự có chuyên môn quản trị kinh doanh ở Văn phòng biến đổi khí hậu sang bộ phận khác cho phù hợp với chuyên môn. Với vị trí kế toán của văn phòng cũng có thể tinh giản bằng cách chuyển nhiệm vụ kế toán của Văn phòng sang kế toán của Sở Tài nguyên và Môi trường Thành phố (tăng thêm phụ cấp công việc cho kế toán của Sở). Làm như vậy, sẽ còn trống 02 biên chế và hoàn toàn có thể tuyển thêm 02 nhân sự có chuyên môn phù hợp vào mà vẫn không làm tăng biên chế chung.

Về giải pháp lâu dài, nguồn nhân lực cốt lõi không có chuyên môn về biến đổi khí hậu cũng cần phải được tạo điều kiện để tham gia các khoá tập huấn về biến đổi khí hậu trong và ngoài nước. Các khoá bồi dưỡng là cách thức hiệu quả giúp vừa nâng cao kiến thức về chính sách, ứng phó biến đổi khí hậu, vừa giúp cập nhật mới những kiến thức này.

Ngoài ra, Thành phố cần tiến hành thống kê, rà soát lại toàn bộ nhân sự đang phụ trách kiêm nhiệm nhiệm vụ ứng phó biến đồi khí hậu trong bộ máy chính quyền địa phương của toàn Thành phố. Mục đích của việc rà soát này là để nắm số lượng nhân sự bổ trợ mà Thành phố đang có làm cơ sở cho việc xây dựng kế hoạch bồi dưỡng hàng năm và dài hạn. Đội ngũ này khi được bồi dưỡng bài bản sẽ tham gia tích cực và hiệu quả vào quá trình tham vấn xây dựng và thực hiện chính sách ứng phó biến đồi khí hậu của Thành phố.

\section{Kết luận}

Với vai trò quan trọng trong quá trình hoạch định và thực hiện chính sách ứng phó biến đổi khí hậu ở Thành phố Hồ Chí Minh, nhân lực về biến đổi khí hậu cần được quan tâm và phát triển một cách thoả đáng cả về trước mắt và lâu dài. Để nguồn nhân lực của Thành phố có thể đảm đương trách nhiệm quản lý nhà nước về ứng phó biến đổi khí hậu, và cụ thể là quá trình thực hiện chính sách ứng phó biến đổi khí hậu, trong thời gian tới, Thành phố Hồ Chí Minh cần tiếp tục thực hiện một số giải pháp. Trước hết, Thành phố cần bổ sung thêm biên chế cốt lõi có chuyên môn về biến đồi khí hậu và chính sách để có thể đảm đương tốt hơn nữa vấn đề biến đổi khí hậu của Thành phố. Tiếp theo, Thành phố cần có kế hoạch bồi dưỡng ngắn hạn và dài hạn cho nhóm nhân lực cốt lõi và bổ trợ cũng cần phải được xây dựng trong ngắn hạn và dài hạn. Kế hoạch bồi dưỡng cũng cần phải được thực hiện một cách hiệu quả trên thực tế. Nói cách khác, cần thiết phải nâng cao năng lực quản lý nhà nước về ứng phó biến đổi khí hậu cho cán bộ, công chức, viên chức đang công tác trong lĩnh vực ứng phó biến đổi khí hậu. Không những vậy, Thành phố còn đặt ra nhiệm vụ thường xuyên nâng cao kiến 
thức, trình độ về chuyên môn, nghiệp vụ, tích hợp các yếu tố biến đổi khí hậu vào quản lý đô thị cho cán bộ quản lý trong Ban Chỉ đạo, Tổ chuyên viên và các cơ quan, đơn vị liên quan.

\section{Tài liệu tham khảo}

[1] ADB, Brief report: Ho Chi Minh City is adapting to climate change, Mandaluyon, Philipines, 2010 (in Vietnamese).

[2] B. Ferman, When failure is success: implementation and Madisonian Government, In Palumbo DJ, Calista DJ, (eds). Implementation and the Policy Process: Opening up the Black Box. Greenwood Press, New York, 1990.

[3] D. Mazmanian, P. Sabatier, Implementation and Policy.Scott Foresman, Chicago, 1983.

[4] Nguyen Huu Hai, Public policy: Basic issues (second edition), National Political Publishing House, Hanoi, 2016, (in Vietnamese)

[5] T.B. Smith, The study of policymaking in developing nations, Policy Studies Journal, 1 (1973), 244-249. doi:10.1111/j.1541-0072.1973.tb00108.x.

[6] A.R. Khan, S. Khandaker, A Critical Insight into Policy Implementation and Implementation
Performance, Public Policy and Administration 15 (4) (2016) 538-548.

[7] G. Kostka, Barriers to the implementation of Environmental Policies at the Local Level in China, Policy Research Working Paper 7016, World Bank Group, Development Research Group Environment and Energy Team, August 2014.

[8] Jica, Final report on proposal of a policy framework for GHG inventory and implementation of GHG emission reduction actions in accordance with HCMC conditions, Ho Chi Minh City, 2017 (in Vietnamese).

[9] Department of Natural Resources \& Environment, Statistics of the Department's payroll situation, Ho Chi Minh City, 2019 (in Vietnamese).

[10] Vietnam Environment Administration, Lack of human resources to respond to climate change, 2012, http://vea.gov.vn/vn/truyenthong/biendoikhihau/P ages/Thiếu-nhân-lực-ứng-phó-biến-đổi-

kh\%C3\%AD-hậu-.aspx (accessed 15 October 2019) (in Vietnamese).

[11] Nguyen $\mathrm{Vu}, \mathrm{A}$ severe shortage in human resources to respond to climate change, 2014, http://www.biendoikhihau.hochiminhcity.gov.vn/ TinTuc/tintuc/Lists/Posts/Post.aspx ?CategoryId=9 \&ItemID $=585 \&$ PublishedDate $=2014-08$ 29T02:00:00Z. (accessed 10 July 2019) (in Vietnamese). 